\title{
MANIFESTAÇÕES DE TENSÃO E COMPORTAMENTO DE ADAPTAÇÃO DE CRIANÇASS HOSPITALIZADAS
}

\section{INTRODUÇĀO}

\author{
Esther Moraes
}

O propósito deste estudo foi observar as reações das crianças à hospitalização, quando internadas pelo período de aproximadamente 30 horas, a fim de submeterem-se a uma pequena cirurgia como herniorrafia, postectomia ou inversão da túnica vaginal; isto porque observamos suas reações de dessespero e sofrimento, e reconhecemos a nossa falta de experiência para ajudar estas crianças; sentíamos tratar-se de uma situação difícil para.ser suportada por elas.

Devido à falta de vivência de cuidado às crianças nestas circunstâncias, pouco absorvíamos das publicações de psicólogos, psiquiatras e enfermeiras, sobre as causas, interpretações e processos de reações emocionais das crianças à hospitalização; também não aceitávamos com a devida conviç̧ão suas recomendações de cuidados para a profilaxia dos possíveis traumas psicológicos. Em virtude de nossa falta de preparo teórico adequado para observar, entender ou lidar com as reações das crianças à hospitalização, tínhamos uma dúvida: teríamos nós uma resposta adequada às solicitações das crianças na ausência da mãe, a partir da observação de suas reaçōes?

O objetivo do trabalho foi responder às seguintes questões:

1) quais seriam as prováveis manifestações de tensão das crianças?

2) o que poderia a enfermeira fazer para diminuir esta tensão?

3) quais seriam as manifestações de adaptação da criança?

4) como a criança nos utilizaria, para ultrapassar a experiência da hospitalização?

O método de estudo constou de:

(*) Docente de Enfermagem Pediátrica.

Artigo transcrito la Rev. da Esc. de Enf. USP, 5 (1): 44-57 - 1971. 
1 - observação e registro do comportamento de quatro crianças quando hospitalizadas, excluindo os períodos de cirurgia e repouso;

2 - assistência de enfermagem baseada na tentativa de compreensão e aceitação do comportamento de cada criança, considerando este comportamento como sendo a maneira da criança enfrentar a separação da mãe, a cirurgia, o meio hospitalar estranho e os cuidados de enfermagem.

Para melhor clareza definimos os seguintes termos: pressos;

- comportamento (4) - ações observáveis e sentimentos ex-

- recursos da personalidade (4) - processos psicológicos desenvolvidos num indivíduo e que são orientados para manejar os estímulos internos e externos, de tal maneira, que o capacite a buscar satisfação e prazer, ou diminuição de tensão; tórios;

- tensão (7) - um dos aspectos emocionais difusos e transi-

- comportamento de adaptação (13) - satisfação de necessidades.

As evidências do estudo foram: 1) em certos períodos da hospitalização as crianças demonstraram tensão manifestada por tristeza silêncio e outros sinais de sofrimento; 2) se o relacionamento com a enfermeira não pôde diminuir satisfatoriamente as tensões provocadas pela hospitalização nas crianças pelo menos deu a elas oportunidade para, expressando seus sentimentos, serem compreendidas por um adulto; este, a enfermeira, foi o seu ponto de apoio, de onde sentiam que vinha proteção; 3) no nosso entender as quatro crianças apresentaram, passada a manifestação de tensão, comportamento de adaptação ou de criança sadia, ou com ego forte, no entender de Denyes (4).

\section{COLETA DE DADOS E EXECUÇĀO DA ASSISTÊNCIA} DE ENFERMAGEM

O primeiro contacto com os quatro pacientes observados foi feito na sala de exame do ambulatório, a partir do momento que o cirurgião decidia a data da cirurgia. Convidávamos a mãe e o filho para conversar a respeito da operação, visitar a clínica onde ficaria internada a criança, e fornecer-nos dados relativos aos hábitos de alimentação, sono, eliminação, brinquedo e comportamento social da criança. Para verificar as impressões e consequências da cirurgia e hospitalização das crianças, mantínhamos com as mesmas outro contato, por ocasião de seu retorno ao ambulatório, em média qua- 
tro dias após a cirurgia. Verificávamos as alteraçōes de apetite, sono, disposição para brincar, humor, comportamento da criança em relação à incisão e queixas de dor. Finalmente procurávamos saber dos seus comentários e referências ligados à hospitalização, feitos em casa, porque muitas vezes estes eram feitos diretamente conosco.

Relatamos a seguir, nosso relacionamento com as quatro crianças estudadas.

\section{OFELIA}

Menina de três anos e oito meses, foi a primeira criança observada. Ela nos deu a impressão de estar calma. Vagarosamente, Ofélia, a mãe e nós, nos dirigimos do ambulatório para a clínica. Ofélia de mão dada com sua mãe parecia observar tudo. Visitando a unidade de cirurgia infantil chamamos sua atenção para os berços e para as crianças, avisando-a que ela também usaria um pijama igual ao usado pelos pacientes. No terraço, mostrou interesse por uma boneca, praticamente de sua altura. Enquanto obtínhamos, com a mãe, informação sobre seus hábitos, a criança afastou-se de nós para apanhar e observar alguns brinquedos que se encontravam no chão. A mãe informou que Ofélia aceita mamadeira, tem preferência por frutas, leite, biscoito e mais especialmente bolo; dorme com luz fraca, chorando às vezes por estar com sêde; brinca mais sozinha e prefere bonecas; é desembaraçada, canta, dança e dá risada; reaše às vezes agressivamente tentando dar sôcos na mãe; quando necessário é disciplinada com ralhos e tapas; quando ela se mostra aborrecida, a mãe costuma elogiá-la, colocá-la no colo e dar-lhe balas. Havia feito tratamento na neurologia e tinha uma receita de Comital. No ambulatório do hospital, reage com choro às injeçōes que lhe são aplicadas.

Em seguida falamos diretamente a Ofélia:

— "Você vai ser operada?"

- (acena sim com a cabeça)

— "O que é?"

- (sorri)

- Mostramos no seu abdome o local da operação. Seria uma hernirrafia.

- (acena com a cabeça)

- "Você vai dormir aqui uma noite; vai ficar longe da mamãe".

— "Não".

- (mãe) "Você fica com a moça".

- (acena sim com a cabeça). 
Dissemos que ela poderia brincar no hospital e recomendamos para trazer sua boneca.

Sentindo uma certa apreensão da mãe perguntamos se a menina era mimada. A mãe refletiu e observou que talvez a mimasse em exagêro. Prevendo sua dificuldade em ajudar a criança para a situação da cirurgia, dissemos que a menina estava reagindo bem e que a melhor maneira de auxiliar Ofélia seria falar-lhe a verdade se houvesse alguma situação de dúvida.

Dia da operação - A mãe conta-nos espontâneamente que Ofélia tinha passado bem o dia anterior; tinha dormido mais do que o comum, isto é, dormira bem à tarde e à noite. Em casa tinha falado à tia: "Eu vou para o hospital, vou ficar sozinha, vou ser operada". Relatou a mãe ainda que, ao chegar à unidade, a criança pedira para descer do colo, a fim de brincar com as outras crianças.

No pré-operatório Ofélia aceitou bem as tomadas de TPR, peso e vestiu o pijama; dissemos-lhe que iríamos aplicar-lhe uma injeção; ela nos acompanhou e consentiu que desabotoassemos o pijama. Chorou após a injeção. A mãe a tomou ao colo e assim ela ficou até o momento de ir para a sala de cirurgia, resmungando que queria um pedaço de bolo.

Foi feita herniorrafia inguinal. As 13 horas voltou calma, ainda sob o efeito da anestesia. Quando acordou queixou-se de dor, encolheu a perna; quis chorar, mas quando a mãe mostrou-lhe sua boneca, acalmou-se e dormiu. Mais tarde, bem acordada, em posição de lado, brincou de por e tirar as meias da boneca. As 17 horas, já sentada, aceitou toda a dieta leve: sopa e suco; chorava no entanto, porque queria bolo. As 17,30 horas urinou com facilidade.

Avisamos a mãe que estava na hora de se despedir da criança. Vendo que sua intenção era sair sorrateiramente, encorajamo-la a dizer-lhe a verdade, isto é, que iria para casa mas voltaria no dia sequinte para buscá-la. A mãe relutou. Saia e entrava na enfermaria, mas, por fim, despediu-se da filha. Beijou-a e saiu. Ofélia não demonstrou agressividade ou medo, aceitou normalmente a retirada da mãe. Neste momento, aproximamo-nos de Ofélia, ficamos ao seu lado enquanto ela brincava com sua boneca. Depois de longo silêncio, olhou para nós e pediu a boneca grande da clínica. Atendendo-a, colocamos a boneca ao seu lado, no berço. Sorriu. Vendo-a aparenmente satisfeita, despedimo-nos e recomendamos Ofélia ao pessoal da clínica.

Ofélia passou bem a noite. Aceitou a mamadeira e estava cuidando de sua boneca quando chegamos, no dia seguinte pela manhã. Respondeu sorrindo às nossas perguntas. Sua mãe chegou logo em seguida a expressão de Ofélia mudou completamente. Chorou, pareceu desconsolada e pediu para sentar no colo da mãe. No colo, foi 
por esta tranquilizada e acariciada. Parando de chorar reclamou e pediu bolo.

Passado o chôro, vestimos Ofélia. Reclamou que a roupa estava pegando no corte. Nós a colocamos de pé e, andando foi tomar a refeição à mesa com os outros pacientes. Recusou o café e pediu água. Aceitou uma gema de ovo com bolachas e depois exigiu mais uma gema. Entreteve-se observando as outras crianças. Na saída da clínica, por sugestão da mãe, nos deu um beijo e também à enfermeira da clínica. Observando o ambiente hospitalar, saiu carregada pela mãe.

De volta ao ambulatório, reconheceu-nos e sorriu. Segundo as observaçōes da mãe a menina estava mais calma em casa e fazia questão de contar para todas as pessoas que iam visitá-la, que fora operada.

\section{EDSON}

Edson, menino de onze anos, deveria ser operado de herniorrafia inguinal e postectomia. Observamos Edson na sala de exame do ambulatório, acompanhado de sua mãe, quando foi marcada a sua cirurgia.

Nesta ocasião não conversamos com ele porque já nos havíamos comprometido a acompanhar um bebe. Entretanto, não tendo comparecido o bebê, resolvemos procurar Edson, mesmo sem ter tido um contato anterior, a fim de prepará-lo para a cirurgia e hospitaìzação.

Chegando à clínica encontramos Edson já com macacão do hospital. No terraço cuidava atenciosamente e em grande atividade das crianças menores. Dava especial atenção a uma criança recémadmitida empurrando-a num andador para fazê-la parar de chorar. Fazia as vezes de pajem. Chamamos Edson para verificar seu estado emocional e informá-lo de que nós cuidaríamos dele; conversamos sobre sua operação. Pouco à vontade, mas, atendendo prontamente, sentou-se ao nosso lado no banco do terraço. Depois das apresentações perguntamos onde é que ia ser feita a operação. Indicou-nos somente o local para a herniorrafia. Perguntamos se 0 penis às vezes não doia para urinar. Confirmou com aceno de cabeça. Então fizemos um desenho esquemático de um corpo humano. Pareceu interessado. Indicamos os locais das cirurgias e explicamos que ele iria tomar uma injeção e dormiria para não sentir dor na hora da cirurgia. Para cada explicação esperávamos por uma pergunta. Com a cabeça baixa, ele nos ouviu atentamente e em silêncio. Dissemos a ele que se quizesse fazer-nos perguntas, poderia. Como não fizesse nenhuma indagação sugerimos que continuasse a cuidar das crianças 
menores. Levantou-se como a mola que pula ao ser descomprimida. Imaginamos que o assunto da operação não era fácil de ser tratado por Edson. Passados uns instantes, procurou-nos para saber o que deveria fazer com o bebê que estava chorando; sugerimos que continuasse empurrando a criança no andador. Posteriormente verificamos que andava livremente pela enfermaria e, em companhia das crianças da clínica, ia ao parque infantil.

Pós operatório - De volta da sala de operação, às 11 horas, Edson chegou acordado. Perguntamos se sentia dor. Respondeu-nos "pouco". Dormiu a maior parte da tarde, sempre com a cabeça coberta pela colcha. Às 17 horas o acordamos para jantar e dissemoslhe:

— "Edson, você já operou".

- "Graças a Deus"! (virando-se e olhando para nós). "Onde está o corte?".

— "Quer ver?"

— "Não, depois".

— "Quer urinar?"

— “Não”.

Aceitou uma tigela de suco. Virou-se e ajetou-se para dormir.

Na manhã seguinte, o convidamos para se levantar. Ajudamo-lo a fletir as pernas passiva e depois ativamente. Auxiliamo-lo a calçar os seus quedes e a caminhar em direção ao banheiro. Andou um pouco com o corpo fletido para a frente. Tomou banho sozinho. Do lado de fora do box do banheiro perguntamos:

— "Como foi a operação?"

— "Não vi nada. Tomei a injeção que a senhora disse e dormi".

Aparentemente satisfeito pediu-nos um pijama folgado. No café comeu com apetite. Quando fomos descascar seu ovo, adiantouse e disse que o faria sozinho. Perguntamos então:

— "Quem vem buscar você?"

— "Minha mãe".

Parecia seguro. Quatro dias depois fomos procurá-lo no ambulatório, para saber como havia passado em casa. As informaçōes foram: formou uma bolinha no local da operação, depois murchou; gostou do hospital porque foi ao parque infantil. Com a ajuda da 
mãe afirmou que teve medo da injeção e do termometro, e dormiu de cabeça coberta porque sentiu frio e teve vergonha de pedir cobertor. A mãe esclareceu "ele é muito nervoso".

\section{MILTON}

Menino de um ano e sete meses, deveria ser operado de herniorrafia e postectomia. Foi trazido ao hospital pela tia, pessoa responsável pelo menino porque a mãe estava hospitalizada.

Apesar da pouca idade, já havia sido internado quatro vezes. Recebe mamadeira três vezes ao dia e mais as refeiçōes com sal. Não come sozinho, não usa urinol. Dorme uma vez durante o dia, usa chupeta. Brinca com as outras crianças de casa e com os adultos. O brinquedo preferido é carrinho. Em geral é uma criança calma. Quando chora é carregado no colo. Engatinha e anda somente apoiando-se nos móveis.

No dia da cirurgia observamos que no colo da tia se apresentava calmo, apesar do jejum. Chamado para a cirurgia, recebeu a injeção de pré-anestésico e foi chorando para a sala de operação. As 12,30 horas voltou da cirurgia agitado e chorando. Ao ser colocado o termômetro em sua axila chorou mais forte. Aprersentava 36C. Foi medicado para dor.

Naquele momento a tia foi para casa cuidar das outras crianças. Pegamos Milton no colo, mas, continuou chorando, provavelmente nos estranhou. Continuamos com ele no colo e cantamos para acalmá-lo. Oferecemos a chupeta, chamamos sua atenção para os desenhos de Walt Disney pintados na parede da enfermaria. Olhou e sorriu. Dormiu.

Às 17 horas aceitou sopa; não aceitou água ou suco. Ae 17,30 horas estava calmo, não chorava. Brincou com seu carrinho vermelho. Sua fisionomia era de satisfação e batia os pezinhos na cama. Estendemos os braços de longe mostrando que queríamos pegá-lo ao colo. Estendeu os seus e aceitou o convite.

Esta criança dormiu bem à noite, aceitou a mamadeika da noite e a refeição da manhã seguinte. Infelizmente não presenciamos sua saida do hospital, como também não o encotramos na data marcada para o retôrno ao ambulatório.

\section{LUIZ ANTONIO}

Seria hospitalizado para uma herniorrafia e inversão de túnica vaginal. Tinha seis anos. Depois de mostrar-lhe a clínica onde ficaria internado obtivemos informaçōes sobre seus hábitos e costumes. O fato mais significativo era tratar-se da primeira hospitalização para um menino da zona rural. Tem bom apetite, preferência 
por frutas, deita-se a acorda cedo; seus brinquedos preferidos são caminhão e automóvel. Perguntamos à mãe se ela teria alguma recomendação especial sobre Luiz Antonio, pois só poderíamos cuidar bem dele conhecendo seus hábitos. Explicou-nos que o menino era calado e nós deveríamos "puxar pela boca" para ele falar, e deveríamos "oferecer para ir ao banheiro e mostrar a sua cama".

Tentamos conversar com Luiz Antonio mas não obtivemos respostas. De cabeça baixa manteve-se calado. Não insistimos.

Verificando que a mãe não tinha recebido nenhuma orientação sobre a cirurgia, explicamos com o auxílio de um desenho os locais da operação e como seria feita a anestesia. Luiz Antonio, sentado no mesmo banco, observou nossa conversa, mas comportou-se como se ele não fosse o principal interessado. Não dirigiu o olhar para nós. Assim mesmo, dissemo-lhe que iríamos cuidar dele quando viesse para o hospital e recomendamos que trouxesse de casa seu brinquedo preferido. De mãos dadas, ele e a mãe sairam calmamente pelo corredor da clínica.

Dia da admissão - calado e cabisbaixo observava a clínica com tensão.

A mãe ajudava-o a vestir o pijama. Luiz Antonio resmungou irritado com a mãe. Resistiu um pouco ao ser colocado o termômetro em sua axila. Terminamos as formalidades da admissão acompanhamos sua mãe ao elevador. A fisionomia de Luiz Antonio não mostrava emoção alguma. A mãe fez sinal para que voltássemos para a clínica. Sem se despedir dela a criança acompanhou-nos em direção à enfermaria, e, dados poucos passos, pegou a nossa mão e apertou-a com força. Em silêncio fomos para o terraço. Trocamos algumas palavras sem importância e aí perguntamos:

"Você trouxe o seu caminhão?" "Corremos para o hall dos elevadores para tentar alcançar sua mãe que ia levando na sacola um Wolkswagen de plástico, comłrado especialmente para sua hospitalização; ele voltou com seu carro na mão, mais relaxado. Apresentamo-lhe as crianças da unidade; Luiz Antonio olhou simplesmente para elas; enquanto, rodeados por elas, as atendíamos, Luiz Antonio levantou-se do banco ao nosso lado, puxou seu carro, e, de cara um pouco sisuda, deu chutes no automóvel. Fomos buscar uma bola e o convidamos para jogar. Sorriu e interessou-se pelo jogo.

Durante o jantar, com as crianças à volta da mesa, sentamos entre Luiz Antonio e outra criança que precisava de ajuda para se alimentar. As crianças fizeram inúmeras perguntas para saber quem era Luiz Antonio e o que viera fazer no hospital; como se mantivesse quieto, sem nada responder, respondemos por ele. Da refeição, aceitou com relutância, um pouco da sopa; aceitou na caneca o suco e não na tigela. Terminado o jantar, convidou-nos para jogar bola. Aceitamos seu convite e, após jogarmos um pouco, entramos na enfer- 
maria para arrumar sua cama. Luiz Antonio ficou à nossa volta, andando de um lado para o outro na enfermaria. Perguntamos se um cobertor era suficiente; disse que sim. Apanhou um revólver que estava sobre um dos berços e o colocou em posição de atirar em seu ouvido. Em dado momento nos perguntou:

— "O que é aquele tubo?"

- "É para trazer oxigênio para a tenda "e mostramos como funcionava, abrindo e fechando o registro.

- “Todas as crianças vão ser operadas?"

— "Vão".

Pareceu-nos mais satisfeito. Sorrindo deu uns saltos de alegria dentro da enfermaria. Interpetamos este momento como o término da tensão de Luiz Antonio, desde o momento da admissão. Observamos que andava com liberdade pela enfermaria. Em dado momento nos procurou e pediu para ligar a televisão. Apresentamos a enfermeira da clínica a ele e transmitimos seu pedido. Vendo que já estava mais ambientado despedimo-nos e prometemos visitá-lo no dia seguinte.

Pela manhã, já banhado, estava sentado à mesinha com as outras crianças, com fisionomia descontraída, observando o ambiente. Aproximamo-nos dele e perguntamos como tinha passado a noite. Disse-nos que não dormira bem devido ao barulho dos carros. Levamô-lo para o terraço a fim de que não presenciasse o café, pois deveria permanecer em jejum. Jogamos bola. Luiz Antonio divertiuse com o brinquedo. Ficamos sabendo que não tem bola em casa para jogar, mas que estava acostumado a assistir o jogo aos domingos. Falou-nos dos irmãos mais velhos. Lemos uma estória de um livro com gravuras; Luiz Antonio e mais algumas crianças repetiram a estória; cada um narrava úm trecho. Convidamos Luiz Antonio para entrar na enfermaria; encontramos um jogo de dominó, ele construiu um espécie de escada. E, então, surpreendeu-nos:

- "Você conhece a Maroquinha?"

— "Não. O que é?"

— "Música de rádio!" (cantou uma música inteira com voz bem afinada).

— “Como é?" (queria que ele repetisse outra vez).

— "Você não ouviu?"

Aproximadamente às 10 horas sugerimos que ele fosse urinar e depois lhe aplicamos o pré-anestésico. Não chorou com a injeção. Levamo-lo na maca para a sala de operação. Sua fisionomia era calma. 
Às 13 horas voltou dormindo. Os sinais vitais estavam dentro do normal. Dormiu até as 16,40 horas. Durante o jantar aceitou o suco de limão, mas recusou a sopa.

- "Tia, eu quero fruta".

- "Laranja?"

— "Sim".

Pediu para se sentar e chupou uma laranja.

— "Você deixa a outra aí para eu chupar depois!"

— "Doi a barriga?"

— "Doi um pouco".

Pediu para ajeitar a posição do corpo na cama algumas vezes. Acomodou-se e dormiu. No dia seguinte saiu do hospital em companhia da mãe e do irmão mais velho.

De volta ao hospital, para receber a alta da cirurgia, a mãe nos contou que o menino havia pedido muita água e frutas em casa. Tinha contado que viu o cirurgião colocar um apareiho em sua barriga (realmente, o menino foi submetido à cirurgia de hérnia umbilical quando já havia passado o efeito da anestesia geral usada na cirurgia programada).

Luiz Antonio apresentou-se acanhado e calado no dia do retorno. Apesar disso, quando acompanhava-os à porta da saída do hospital, saiu do lado da mãe e veio, espontâneamente, segurar a nossa mão, mas continuou em silêncio. Perguntamos a ele o que tinha achado do hospital.

— "Gostei".

- "Por que?"

— "Por que lá é lindo".

\section{TENTATIVA DE RELACIONAR OS DADOS OBSERVADOS}

A seguir, apresentamos, em breve citação, uma tentativa de classificar os fatos encontrados, em respostas às perguntas iniciais deste estudo, baseados apenas na observação das quatro crianças.

A - Sinais de provável presença de tensão:

1 - dificuldade para se relacionar (não fala, nega-se a responder) ;

2 - crise de chôro;

3 - atividade motora exagerada ou rigidez muscular (mão, rosto, tronco, membros). 
B - Atitudes da enfermeira para diminuir a tensão:

1 - compreender a necessidade de atividade motora (oferecer chupeta, sugerir para empurrar criança no andador, chutar a bola, não impedir o movimento da criança);

2 - proporcionar a aceitar proximidade física (oferecer colo, dar a mão, sentar-se ao lado da criança);

3 - distrair a atenção da criança com estímulos do ambiente (pinturas na parede);

4 - estimular a comunicação da criança (mostrar interesse por ela, por exemplo: "Eu vou cuidar de você"; respeitar seu sílencio e responder às suas perguntas).

C - Manifestação de adaptação da criança $\left(^{*}\right)$ :

1 - protesta diante de procedimento desagradáveis e ameaçadores;

2 - expressa verbalmente sentimentos de prazer, raiva e desconforto;

3 - procura ajuda fazendo perguntas;

4 - procura, ativamente, as pessoas para receber conforto e apoio;

5 - aceita dependência quando apropriada;

6 - toma iniciativa de atividade independente;

7 - anda, explora e brinca livremente;

8 - enfrenta a realidade de experiências desagradáveis; e

9 - persiste em tentativas para resolver seus problemas brincando e verbalizando.

\section{CONCLUSÕES}

A observação das quatro crianças, nos fêz concluir que elas sofreram traumatismos emocionais por experiências novas ou desagradáveis em algum período de sua internação. As implicações de separação da mãe, experiências ameaçadoras de controle de temperatura, cirurgia e tratamentos, especialmente injeções, o ambiente e as pessoas estranhas, são causas de ansiedade e tensão nas crianças hospitalizadas, fato bem estudado pelos autores indicados na bibliografia $(1,2,3,4,5,6,7,8,9,11,12$ e 14$)$.

Apontamos algumas atitudes da enfermeira, aparentemente úteis para diminuir as manifestações de tensão. É mais um esforço quanto

(*) Adaptação de critério para avaliação de aumento de energia do ego, in DENYES, M. J. - A child with Hirschsprung's disease uses a nurse to gain ego strength. ANA Clinical Sessions, Dallas, 1968, p. 157. 
a alguns aspectos de se dar apoio à criança hospitalizada muito bem indicados por Denyes (4), Post (11), Schahill (12), Blake (1,2) e Smith (14).

Os autores Blom (3) e Langford (8) reconheceram que muitas crianças reagem surpreendentemente bem às experiências de dor e medo, no meio hospitalar, demonstrando capacidade de resistência e açaptação. Jessner (6) cita casos em que a hospitalização foi uma experiência construtiva e considerada pela criança como motivo de ganho de seu prestígio. Nas quatro crianças estudadas, apesar do curto período de hospitalização, observamos as características de comportamento considerados por Denyes como um critério de ganho de capacidade do ego, que no nosso entender são manifestações de comportamento de adaptação da criança, para enfrentar a realidade da experiência no hospital.

As quatro crianças aceitaram a dependência da enfermeira para o atendimento de suas necessidades, obtenção de carinho ou diminuição de tensão. A dependência não foi forçada; pelo contrário, foi permitido que elas fossem dependentes até que ganhassem forças para serem independentes (14). As quatro crianças utilizaram a enfermeira no momentos de tensão, para obter proteção, conceito já apresentado por Jessner (6) e Blake (2).

Em relação ao preparo das crianças para cirurgia, pensamos, como Jessner, que teve efeito relativo. Não houve tempo suficiente para as crianças aceitarem o assunto para conversar, quanto mais para substituir possíveis conceitos ou fantasias errôneas, encontrados muitas vezes nas crianças. No entanto, imaginamos que foi útil, a fim de dar oportunidade às mães para se esclarecerem a respeito. Pensamos que tenha sido útil para diminuir (9) a ansiedade das mães e consequentemente a transmitida aos filhos.

A dificuldade das mães de se despedirem de seus filhos merece atenção da enfermeira. As mães saem sorrateiramente ou dão uma explicação não verdadeira para evitar o choro das crianças. Blake (1) salienta que a enfermeira precisa explicar às mães a necessidade de encararem a realidade, para não aumentar o medo das crianças de serem abandonadas. Smith (14) afirma que a despedida é necessária para mantér a confiança da criança na mãe.

O brinquedo, neste estudo, foi considerado apenas para atendorr à necessidade da criança que tem um laço com sua casa e de representar um sinal de sua identidade (6).

Achamos que seria interessante pesquisar dois grupos comparáveis de crianças, um de controle e outro expermental, na situação de uma pequena cirurgia, por período médio de 30 horas de hospitalização, para verificar se o relacionamento da criança com uma enfermeira, que atende convenientemente suas necessidades de de- 
pendência e depois de independência, diminui as manifestações de tensão, causadas pelos impactos emocionais da internação.

E necessário explicar que não houve um preparo prévio sobre o modo de nos relacionarmos com as crianças. No entanto, agora, ao redigirmos suas características, dez meses após o término do estudo, reconhecemos identidade entre o nosso comportamento e algumas considerações de Moustakas (10) sobre os elementos eficientes para um relacionamento terapêutico com a criança, visando o seu equilíbrio emocional.

Supondo que tenha sido assimiladas as idéias deste e de outros autores, quanto à melhor maneira de agir para auxiliar o desenvolvimento mais favorável da personalidade da criança, conceituamos a atitude da enfermeira que quer ajudar a criança, na adaptação ao hospital, do seguinte modo:

1 - uma atitude de espera, de quem quer ouvir e ver expressos os sentimentos da criança;

2 - ao perceber certa ansiedade na criança, ajudá-la a exteriorizar suas dúvidas, medos, ressentimentos e tensões;

3 - fazê-la sentir que estamos participando de sua experiência emocional, permanecendo junto dela;

4 - fazê-la sentir que atendemos sua solicitação de proteção (2) ;

5 - fazê-la sentir que esperamos suas decisões e compreendemos seus desejos de independência para buscar a satisfação de suas necessidades e para expressar mais espontâneamente suas emoções, inclusive sua demonstração de que não aceita ou não necessita mais de nossos cuidados.

\section{REFERENCIAS BIBLIOGRAFICAS}

1. BLAKE. F. G. WAECHTER, E. H. - Nursing care of children. 8th el. Philadelphia, Lippincott, 1970. p. 15-18.

2. BLAKE, F. G. - Open heart surgery in children. Washington., Governement Printing Office, 1964. p. 45-83 (Children's Bureau Publication n. ${ }^{\circ}$ 418).

3. BLOM, G. E. - The reactions of hospitalized children to illness. Pediatrics, 22: 590-600, sep., 1958.

4. DENYES, M. J. - A child with Rirchsprung's disease uses a nurse to gain ego strength. ANA Clinical Sessions: 155-161, 1968.

5. ERICKSON, F. - Reaction of children to hospital experience. Nursing Outlook. 6 (9): 501-504, sep., 1968.

6. JESSNER, L., BLOM, G. E., WALDFOGEL, S. - Emotional implications of tonsillectomy and adenoidectomy on children., Psychoanal Stud Child, 7: 126-129, 1952. 
7. KRECH, D., CRUTCHFIELD, R. S. - Elementos de Psicologia 2. ${ }^{\text {a }}$ Ed. - São Paulo, Pioneira, 1968. b. 1 p. 298.

8. LANGFORD, W. S. - The child in the pediatric hospital: adaptation to illness and hospitalization. Am. Journ. Orthopsychiatry 31 (4): 667-684, oct., 1961.

9. MAHAFFY, P. R. - The effects of hospitalization on children admited for tonsillectomy and adenoidectomy. Nursing Research. 14 (1): 12-19, Winter, 1965.

10. MOUSTAKAS, C. E. - Children in play therapy. New York, MacGraw Hill, 1953.

11. POST, S. - Hospitaization of children under five. The Canadian nurse. 62 (7): 34-37, july, 1966.

12. SCHAILL, M. - Preparating children for procedures and operations. Nursing Outlook. 17 (6): 36-38, june, 1969.

13. SCHLICHTMANN, K. A. - Adaptive mechanisms in a selected group of burnel patients. ANA Clinical Sessions, 259-266, 1968.

14. SMITH, M. - Ego support for the child patient. Am. Journ. Nursing. 63 (10): 90-95. oct. 1963. 